\title{
Lithological Analysis of Nain Ophiolitic Zone Using ASTER Data
}

\author{
Ali Reza Nasiri Khaneghah*, Ramin Arfania \\ Department of Geology, Isfahan (Khorasgan) Branch, Islamic Azad University, Isfahan, Iran \\ Email: ^ali.nasiri.k@gmail.com,rarfania@gmail.com
}

How to cite this paper: Khaneghah, A.R.N. and Arfania, R. (2017) Lithological Analysis of Nain Ophiolitic Zone Using ASTER Data. Open Journal of Geology, 7, 1200-1214.

https://doi.org/10.4236/ojg.2017.78080

Received: July 17, 2017

Accepted: August 20, 2017

Published: August 23, 2017

Copyright $\odot 2017$ by authors and Scientific Research Publishing Inc. This work is licensed under the Creative Commons Attribution International License (CC BY 4.0).

http://creativecommons.org/licenses/by/4.0/ (c) (i) Open Access

\begin{abstract}
The Mesozoic ophiolitic Mélange, north of Nain in the Central-East Iran Microplate (CEIM) comprises serpentinized ultramafic rocks, harzburgites, dunite, gabbro, peridotite, pelagic limestone and other carbonate rocks. The excellent and vast exposure of this desert region is well suited for geologic mapping of this rock suite using remote sensing, especially using data from the satellite-borne advanced Space borne Thermal Emission and Reflection Radiometer (ASTER) imaging system which was designed for mapping mineral information. In this study, data processing methods like Method Minimum noise fraction (MNF), Feature Oriented Principal Components Selection (FPCS), Band Ratios (BR) and Optimum Index Factor (OIF) were used to process ASTER data to optimize the mapping of ophiolite rock types. For example, a simple color composites of OIF (Red: B3, Green: B4, and Blue: B8) and Band ratios (e.g. Red: $(\mathrm{B} 2+\mathrm{B} 4) / \mathrm{B} 3$, Green: $(\mathrm{B} 5+\mathrm{B} 7) / \mathrm{B} 6$, Blue: $(\mathrm{B} 7+$ B9)/B8) were useful for discriminating serpentinite, meta-basalt and granite rock types. It is concluded here that proposed ASTER data has the potential for mapping similar ophiolites elsewhere using the global archive of ASTER imagery.
\end{abstract}

\section{Keywords}

Ophiolitic Mélange, Ultramafic Rocks, Advanced Space Borne Thermal

Emission and Reflection Radiometer (ASTER), Optimum Index Factor (OIF), Feature Oriented Principal Components Selection (FPCS), Band Ratio (BR)

\section{Introduction}

Nain Ophiolitic Complex with an area of approximately 500 square kilometers is located approximately $100 \mathrm{~km}$ northeast of Esfahan in Iran (Figure 1). The northwest-southeast trend of the ophiolite belt extends for approximately $40 \mathrm{~km}$ 


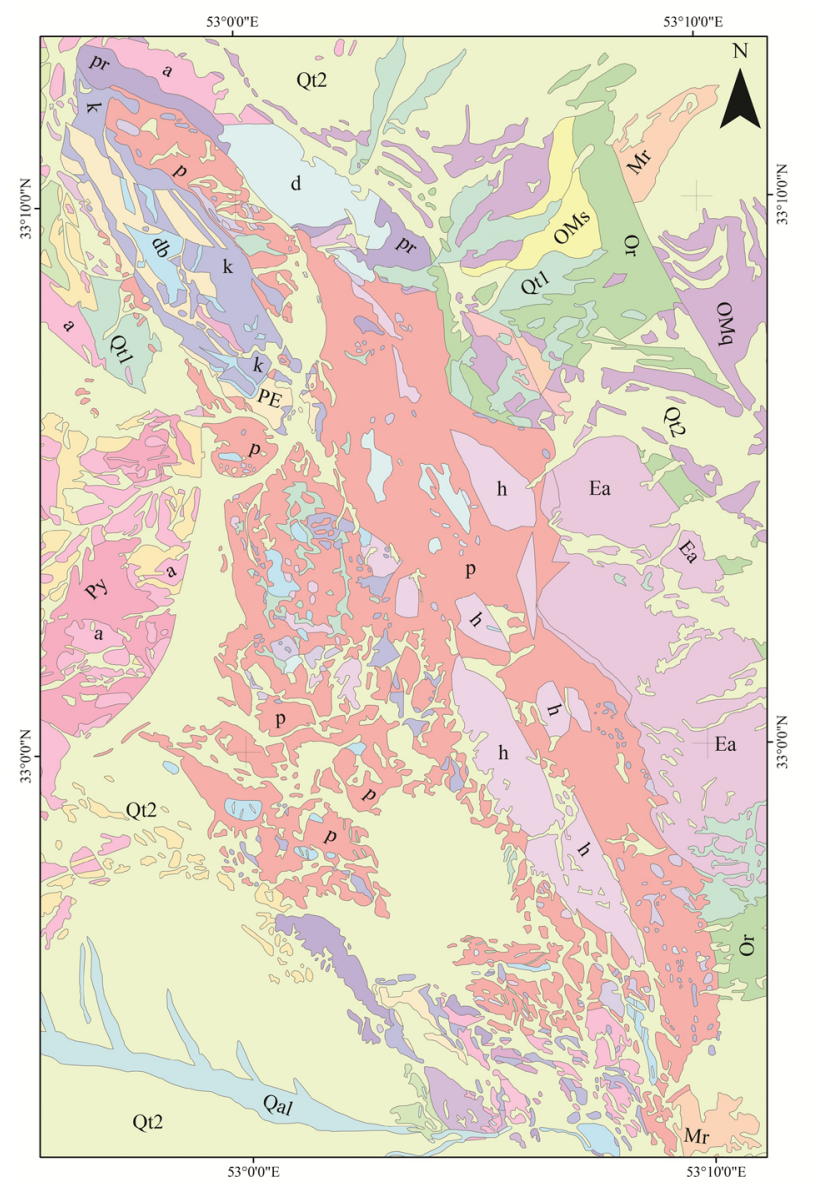

\section{Geological map of North Nain}

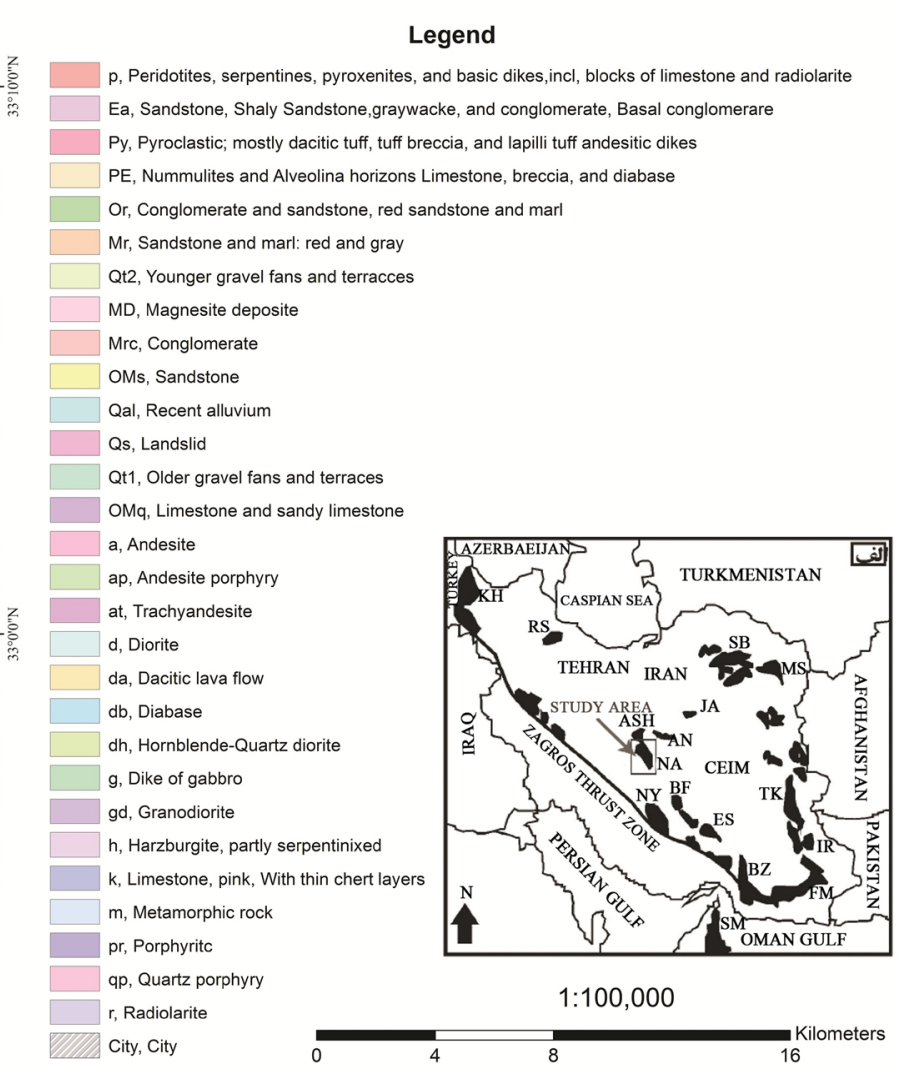

Figure 1. Geological map of the study area [1].

from the city of Nain in the south to the villages of Seprabvand Paco-Sohail in the north and northwest respectively [1] [2] [3]. There have been numerous studies of ophiolites in Iran [1] [3] [4] [5] [6].

Today, applying aerospace technologies for terrestrial data collection is very common to investigate and identify the sources without physical contact [7] and generally, Remote Sensing data are available in digital and pictorial forms [7]. Using various remote sensing information is usually in economic resource exploration deposits and prospects [8]. In fact, we should collect information for mining exploration; so the first step in exploration by data processing in remote sensing is providing satellite images from the study area. Then, we study the conventional processing methods that can be used in altered areas detection and lithological units are studied and finally data evaluation and identification of stones has been done. The data used in this study are related to the ASTER sensor (Advanced Space borne Thermal Emission and Reflection Radiometer). ASTER Sensor is one of the imaging sensors carried by the Terra satellite that was launched in December 1999. A multispectral sensor has high resolution and data are in three ranges like VNIR (visible and near-infrared), SWIR (Short Wave Infrared) and TIR (Thermal Infrared) [9]. Stone showed the best absorption or reflection in different wavelength bands. In fact, the best relationship 
between the wavelength and ophiolite is absorption band of $0.49,0.59,2,17$ and 23 micrometers [10]. This study inventively consists of two steps. The first step is threshold calculation with $98 \%, 95 \%$ and $92 \%$ confidence level. In the second step we use Justice and Townshend's formula for estimated locational accuracy in the number of pixels and then, using the Cochran formula, the number of samples is introduced in principle. This study tends to using remote sensing methods such as composite band, the band ratio, feature oriented principal components selection and at last validation of feature oriented principal components analysis for detection of ophiolite areas in the north of Nain.

\section{Geography and Geology of the Study Area}

The study area, Nain ophiolite is located within the $53^{\circ} 00^{\prime} 00^{\prime \prime}$ to $53^{\circ} 07^{\prime} 00^{\prime \prime}$ East length and $32^{\circ} 52^{\prime} 00^{\prime \prime}$ to $33^{\circ} 00^{\prime} 00^{\prime \prime}$ northern latitudes (Figure 1). In other words, it is between 1: 100,000 Kajan, Zavareh, Shahrab, Nain map as well as 1: 250,000 Anarak and Nain map. In fact, the basic study area is located in the Urmia girl's volcano-plutonic arc. Nain's Ophiolites are from Mesozoic age located as a Color Mélange around the Central Iran's micro continental [3]. Neotethys and Paleotethys, respectively, are considered as their associated oceans [3] [11]. Nain ophiolitic in terms of geology compounds including serpentinized peridotite composed in harzburgites masses with Dunite lenses, Gabbro masses, different kinds of dyke with Pillows and lava tubes, limestone schistosity, nap, upper Cretaceous radiolarians, Limestone Paleocene, conglomerate shale and sandstone of Eocene, marl, Miocene Sandstones Metamorphic rocks of Amphibolite and glaucophane-Jadeite schist Composition. All Ophiolite units are metamorphosed in greenschist facies [12].

\section{Methodology}

There are three main steps in the implementation of the identify Ophiolite Mélange using band ratio techniques, composite band and Feature Oriented Principal Components Selection projects, Figure 2 shows the flow chart, the flow chart was used and includes the following steps:

- Satellite data of ASTER Sensor (LEVEL 1T) derived from TERRA satellite has “AST_L1T_00303082001073110_20150415023833_85285” ID number and 2015/04/15 DATE ACQUIRED.

Aster Level 1T is modified by Aster Level 1. In fact, AST_L1T is a product that including formatting code AST_L1B (Aster LEVEL 1B), radiometric and geometric corrections (AST_L1B is used) and crosstalk correction coefficients [13]. The Aster data has three groups of VNIR, SWIR and TIR bands. The sensor information is written in Table 1 . Before, data should be prepared to enter the processing stage. Before, data should be prepared to enter the processing stage. Preprocessing is essential for preparing data in the study area. First we Layer stack 3 band near-infrared (VNIR) and 6 band SWIR (Short Wave Infrared) data, then convert it to a 9-band image. 


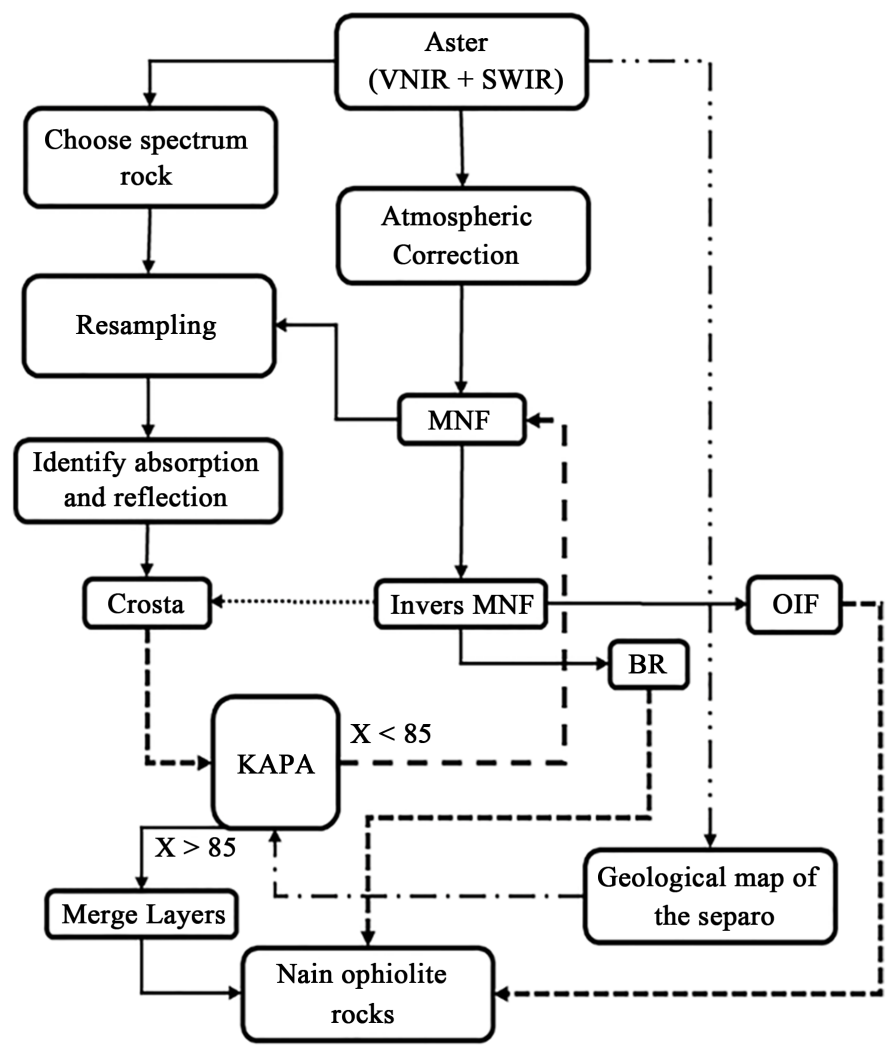

Figure 2. Flow chart of the study progression.

Table 1. Advanced Space borne Thermal Emission and Reflection Radiometer (ASTER) sensor information.

\begin{tabular}{|c|c|c|c|c|c|c|c|}
\hline \multicolumn{8}{|c|}{ Advanced Space borne Thermal Emission and Reflection Radiometer (ASTER) } \\
\hline $\mathrm{Nr}$ & Name & Start WL & Middle WL & End WL & Sp. Rg & Spat. Res. & Comment \\
\hline 1 & VNIR Band 1 & 520 & 560 & 600 & 80 & 15 & - \\
\hline 2 & VNIR Band 2 & 630 & 660 & 690 & 60 & 15 & - \\
\hline 3 & VNIR Band 3N & 760 & 810 & 860 & 100 & 15 & Nadir \\
\hline 4 & VNIR Band 3B & 760 & 810 & 860 & 100 & 15 & Backward \\
\hline 5 & SWIR Band 4 & 1600 & 1650 & 1700 & 100 & 30 & - \\
\hline 6 & SWIR Band 5 & 2145 & 2165 & 2185 & 40 & 30 & - \\
\hline 7 & SWIR Band 6 & 2185 & 2205 & 2225 & 40 & 30 & - \\
\hline 8 & SWIR Band 7 & 2235 & 2300 & 2365 & 130 & 30 & - \\
\hline 9 & SWIR Band 8 & 2295 & 2330 & 2365 & 70 & 30 & - \\
\hline 10 & SWIR Band 9 & 2360 & 2395 & 2430 & 70 & 30 & - \\
\hline 11 & TIR Band 10 & 8125 & 8300 & 8475 & 350 & 90 & - \\
\hline 12 & TIR Band 11 & 8475 & 8650 & 8825 & 350 & 90 & - \\
\hline 13 & TIR Band 12 & 8925 & 9100 & 9275 & 350 & 90 & - \\
\hline 14 & TIR Band 13 & 10250 & 10600 & 10950 & 700 & 90 & - \\
\hline 15 & TIR Band 14 & 10950 & 11300 & 11650 & 700 & 90 & - \\
\hline
\end{tabular}


At last we will make the necessary corrections including geometric correction and atmospheric correction. AST_L1T images have basic correction, geometric correction was not made. Due to the lack of sufficient meteorological information such as water vapor pressure; visibility and temperature of the air, the IARR (Internal Average Relative Reflectance) atmospheric correction method has been used. Finally, MNF (Minimum Noise Fraction) is used for noise fraction and the variation of noise in all bands is the same. When the noise is in a clause, we reduce it with multiple linear regressions. By changing the MNF space, we remove the noise, and then the bands become the original space [14]. The band with MNF's eigenvalues less than 1.2 is considered as a noise and we do inverse MNF otherwise we use the image before the MNF, which is an atmospheric correction. In fact, according to the results of Table 2, we do not need this type of processing.

- We select considered spectrum rocks from ASTER spectral library and resample it according to band spectrum sensor. we should identify absorption and reflection band, then characterize band ratio and OIF (Optimum Index Factor) of best composite band; Finally feature oriented principal components selection analysis is done.

- We perform the validation using geological map that was produced in 1972 by Davoudzadeh [1], and then overall accuracy and Kappa coefficient should be calculated.

\subsection{Data Processing of the Study Area}

A gray level image with equal amount of red, green and blue per pixel. A false color conversion is done by changing colors in the RGB display [15] [16]. False color combination (FFC) is often performed to emphasize the effects or special effects. It's better to use Non-visible bands in false color combination (FFC) and they have more values than single-band images [16]. Each composite band is made of three colors and each color is assigned to a band. Before obtaining composite band using OIF index, 84 triplex composite bands modes should be considered for the 9-band ASTER sensor. In fact OIF index used to select a combination of three bands which is calculated by dividing the three-bands standard deviation to the correlation coefficient absolute value (ABS (CCi)) [17] [18]. The Image Optimum Index Factor is written in Equation (1). The Image Optimum Index Factor is written in Equation (1). In Table 2 the OIF composite band is shown and we can see it in Figure 3. In this figure green Gabbros, red-black dunite and dark green bluish Chromite are obvious.

Table 2. MNF eigenvalues and OIF composite band.

\begin{tabular}{|c|c|c|c|c|c|c|c|c|c|c|}
\hline & Band & B1 & B2 & B3 & B4 & B5 & B6 & B7 & B8 & B9 \\
\hline Number & ASTER & 1104.0 & 152.2 & 52.1 & 24.9 & 13.3 & 11.6 & 9.5 & 6.0 & 3.2 \\
\hline OIF & ASTER & - & - & $\mathrm{R}^{\star}$ & $\mathrm{G}^{*}$ & - & - & - & $\mathrm{B}^{\star}$ & - \\
\hline
\end{tabular}

*The highest OIF is 0.37210387 for RGB: (B3, B4, B8). 


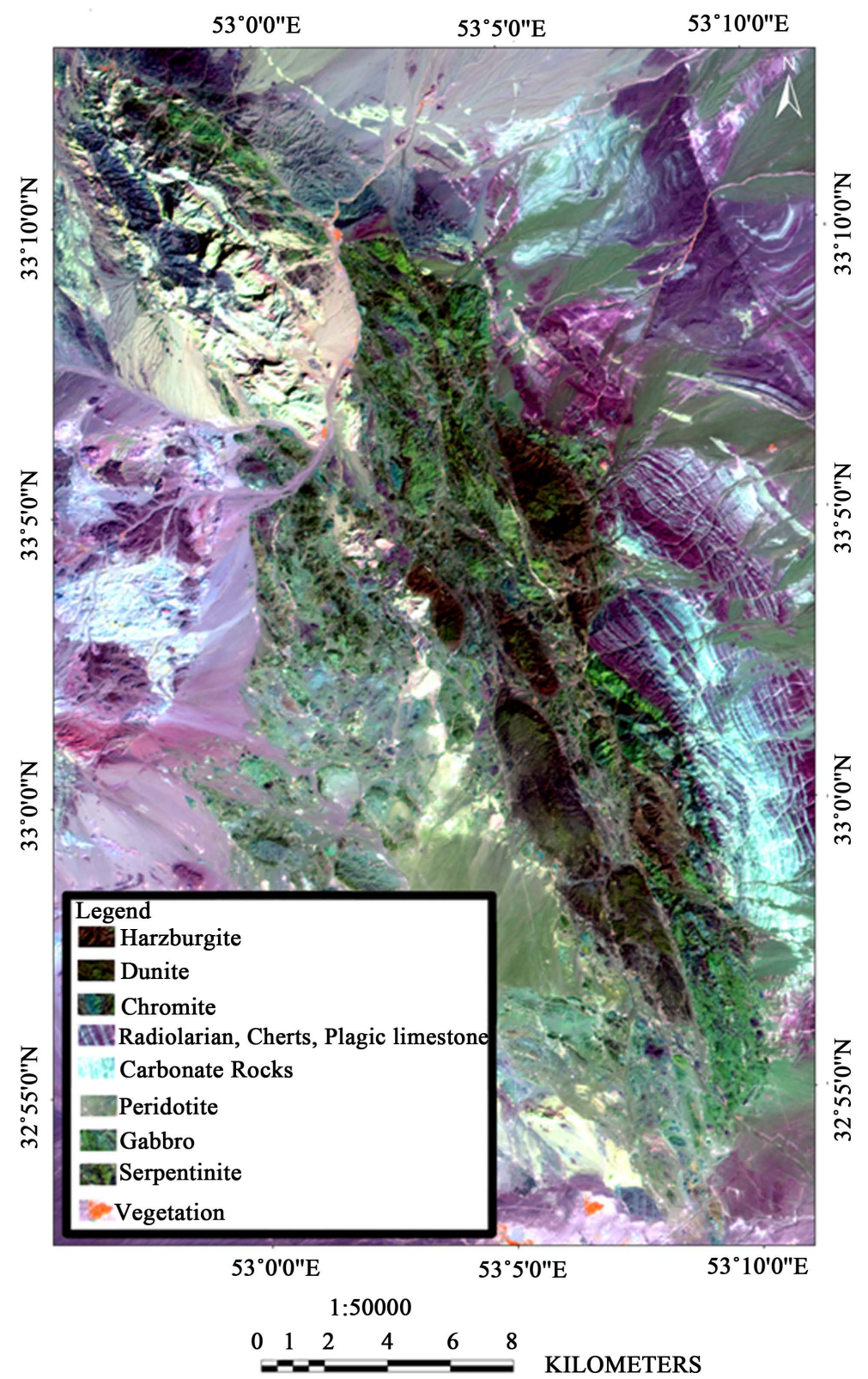

Figure 3. Composite band of OIF index where the green Gabbros and red-black Dunite and Chromite are displayed by dark blue and Vegetation is orange.

$$
O I F=\sum_{i=1}^{3} S D_{i} / \sum_{i=1}^{3} A B S\left(C C_{i}\right)
$$

Spectral rationing is a multi-spectral image processing method which includes dividing one band to another one, (usually after initial corrections for atmospheric path radiation or sufficient movement imposed by the multi-spectral sensor) [19] [20]. Sometimes these images used in Mineralogy index calculation too. They apply in calculating the considered indexes too. Generally, in the band ratio method by recognizing absorption and reflection spectrum specifications of mineral, good bands with the most reflection and absorption are selected. In Figure 4 resampling Spectral diagram the Peredotit-2, Peredotit-4, Pyroxenite, 


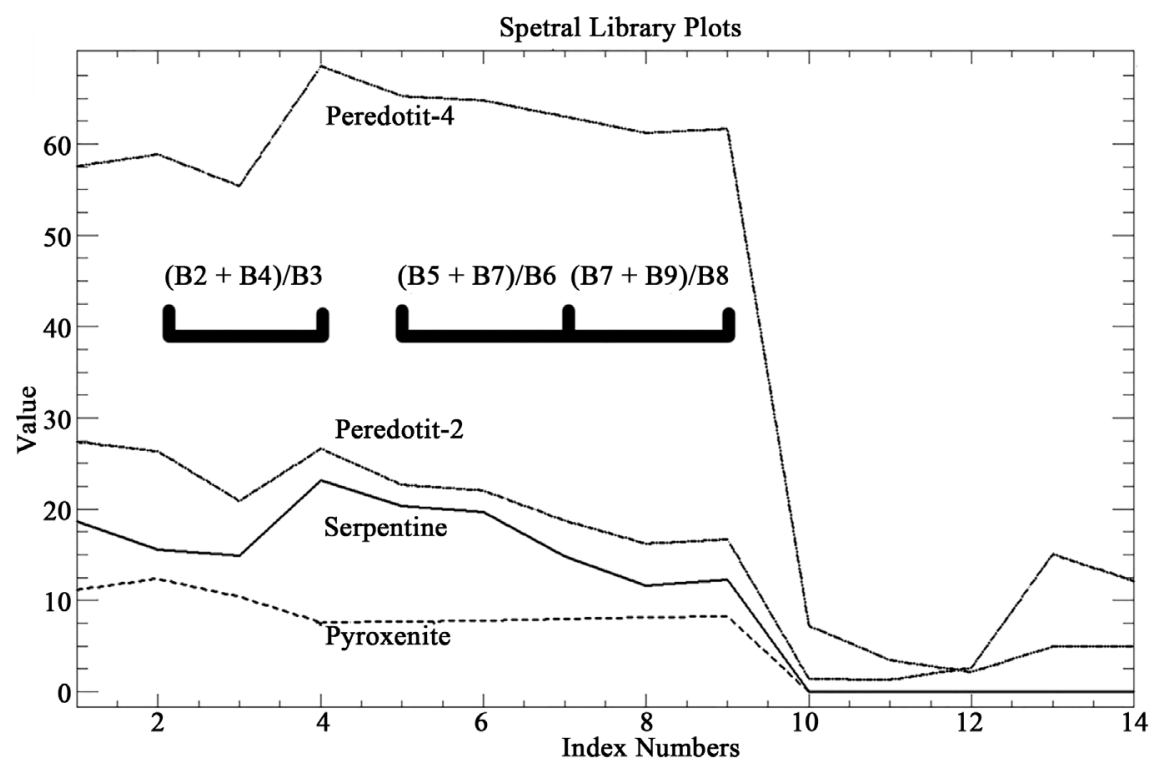

Figure 4. Resampling Spectral diagram the Peredotit-2, Peredotit-4, Pyroxenite, and Serpentine.

and Serpentine are shown. In this paper, we use the composite band of band ratio (R: $(\mathrm{B} 2+\mathrm{B} 4) / \mathrm{B} 3$, G: $(\mathrm{B} 5+\mathrm{B} 7) / \mathrm{B} 6$, B: $(\mathrm{B} 7+\mathrm{B} 9) / \mathrm{B} 8)$ proposed by Amer in 2010 and from now on we call it Amer band ratio [21]. It is shown in Figure 5 where dark pink Chromite, yellow pink Gabbro, orange and pale green Carbonates and dark green vegetation are displayed. In parts B, C and D we can see the threshold for each part of the Amer band ratio. Threshold function used in many types of Spectral minerals algorithms such as procedures based on the interpretation of Spectral knowledge, methods to identify the ultimate goal or the distribution of pixels extractive for maping minerals and rocks. The threshold calculation statistical methods lead to low concentrations removal [22]. At first, the pixel value of each image sets from zero to 255 and then threshold calculation is done using Equations (2)-(4) with 98\%, 95\% and 92\% confidence level. In Figure 5 the threshold for Amer's band ratio is specified.

At Confidence $98 \%$ : Band DNT hreshold $=$ Mean $+3 \times($ Standard deviation $)$

At Confidence $95 \%$ : Band DNT hreshold $=$ Mean $+2 \times($ Standard deviation $)$

At Confidence $92 \%$ : Band DNT hreshold $=$ Mean $+1 \times($ Standard deviation $)$

ASTER sensor's spectral library includes data from three spectral library like Johns Hopkins University (JHU), NASA Jet Propulsion Laboratory's spectral library (JPL) and United States geological Survey Headquarters (USGS). For more information you can refer to the website (https://speclib.jpl.nasa.gov/search-1) which contains the whole Spectrum, Stone, Soil, Mineral, Vegetation and a comprehensive collection of more than 2300 covering products with a wavelength range of 0.4 - 15.4 micrometers [23]. In fact, we choose Peredotit-2, Peredotit-4 rock spectrum (two Peridotite stone with different combinations marked by the numbers 2 and 4), Pyroxenite, and Serpentine from spectral li- 
$\mathrm{R}:(\mathrm{B} 2+\mathrm{B} 4) / \mathrm{B} 3, \mathrm{G}:(\mathrm{B} 5+\mathrm{B} 7) / \mathrm{B} 6, \mathrm{~B}:(\mathrm{B} 7+\mathrm{B} 9) / \mathrm{B} 8$

$(\mathrm{B} 2+\mathrm{B} 4) / \mathrm{B} 3$
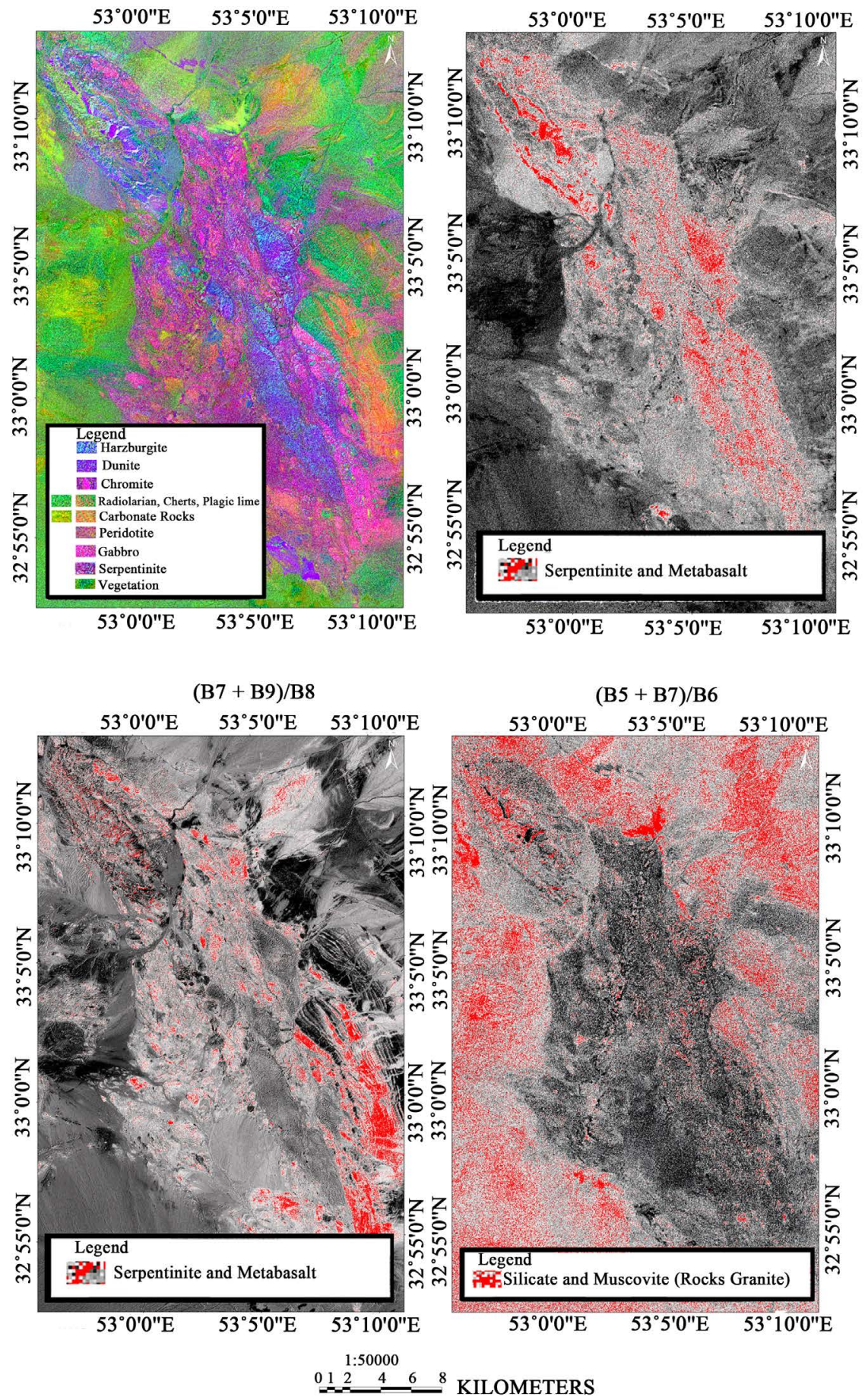

Figure 5. The composite band of Amer's band ratio and Threshold for section of the Amer band ratio.

brary; after that we should specify reflection, absorbtion band according to the spectrum. Lisweanit's reflection and the absorption band are taken from Sankaran Rajendran article [24]. Principal Component's conversion is one of the most popular tools to reduce the dimensionality [25]. 
Generally, it is a linear transformation maximizing the variance by transferring data to a new coordinate system. In Feature Oriented Principal Components Selection (FPCS) we make use of good and well-known bands with appropriate information. In this way, only basic information about minerals, stone and vegetation properties are required and it's based on principal component conversion capabilities in mapping and data variance details in consecutive components. This method is known as Crosta [26], so that 4-bands are selected as 2 absorption and 2 reflection bands (Based on the spectral properties of minerals and Stone). In this method, according to evaluating eigenvector, we can determine which of the principal components reflect the information about spectral signature of specific purpose [27]. The choice of PCs is appropriate in that, in Vector matrix value, the bands absorption and reflection of the target minerals have the highest values at the same time, while these values are also non-symbols [28] [29]. Table 3 shows the Lisweanit stone's eigenvalues matrix and you can see the eigenvalues matrix for Peredotit-2, Peredotit-4, Pyroxenite and Serpentine. Table 4 contains threshold values for the FPCS of Peredotit-2, Peredotit-4, Pyroxenite, Serpentine and Lisweanit. The selected principal component analysis (FPCS) images are shown in Figure 6.

Table 3. Eigenvalues matrix for Peredotit-2, Peredotit-4 and serpentine.

\begin{tabular}{|c|c|c|c|c|c|c|c|c|c|}
\hline \multicolumn{5}{|c|}{ Serpentine } & \multicolumn{5}{|c|}{ Peredotit-4 } \\
\hline${ }^{*} \mathrm{EV}$ & 4 & 6 & 7 & 8 & ${ }^{\star} \mathrm{EV}$ & 1 & 3 & 4 & 5 \\
\hline PC 1 & 0.999 & -0.047 & -0.024 & -0.00 & PC 1 & -0.992 & 0.087 & 0.089 & -0.012 \\
\hline PC 2 & -0.047 & -0.999 & -0.012 & 0.009 & PC 2 & 0.072 & 0.984 & -0.16 & -0.023 \\
\hline PC 3 & 0.023 & -0.013 & 0.999 & -0.03 & PC 3 & -0.102 & -0.153 & -0.98 & 0.033 \\
\hline PC 4 & 0.007 & 0.009 & 0.032 & 0.999 & PC 4 & -0.007 & 0.029 & 0.03 & 0.999 \\
\hline \multicolumn{5}{|c|}{ Pyroxenite } & \multicolumn{5}{|c|}{ Peredotit-2 } \\
\hline${ }^{\star} \mathrm{EV}$ & 2 & 4 & 5 & 9 & ${ }^{\star} \mathrm{EV}$ & 1 & 3 & 4 & 8 \\
\hline PC 1 & -0.999 & 0.024 & -0.031 & 0.025 & PC 1 & 0.99 & -0.14 & -0.04 & -0.06 \\
\hline PC 2 & 0.021 & 0.994 & 0.111 & 0.007 & PC 2 & 0.13 & 0.95 & 0.16 & -0.22 \\
\hline PC 3 & 0.034 & 0.11 & -0.993 & 0.003 & PC 3 & -0.01 & 0.18 & -0.98 & 0.05 \\
\hline PC 4 & 0.025 & -0.008 & 0.003 & 0.999 & PC 4 & -0.09 & -0.2 & -0.08 & -0.97 \\
\hline \multicolumn{10}{|c|}{ Lisweanit } \\
\hline${ }^{*} \mathrm{EV}$ & 4 & 6 & 7 & 8 & & & & & \\
\hline PC 1 & 0.999 & -0.035 & 0.0159 & -0.016 & & & & & \\
\hline PC 2 & -0.036 & -0.998 & 0.012 & -0.031 & & & & & \\
\hline PC 3 & -0.016 & 0.015 & 0.997 & -0.066 & & & & & \\
\hline PC 4 & 0.014 & -0.031 & 0.066 & 0.9971 & & & & & \\
\hline
\end{tabular}

${ }^{*}$ EV: Eigenvector. 

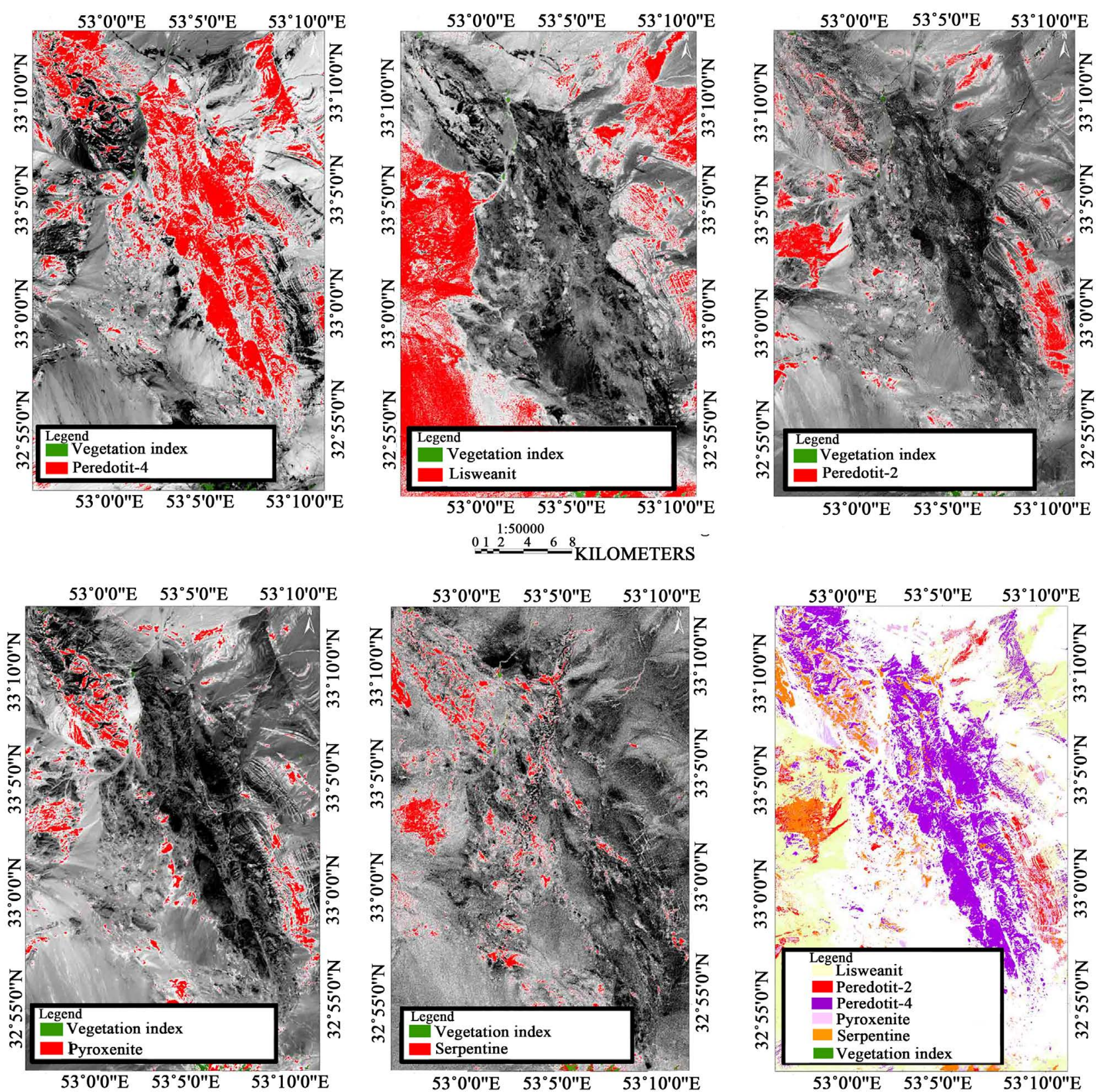

Figure 6. The images obtained by feature oriented principal components selection method.

Table 4. Threshold values for FPCS's Peredotit-2, Peredotit-4, Pyroxenite, Serpentine and Lisweanit.

\begin{tabular}{cccccccccccccccc}
\hline \multicolumn{1}{c}{ Feature Oriented Principal Components Selection (VNIR+SWIR) } & \multicolumn{1}{c}{${ }^{* *} \mathrm{~A}$} & ${ }^{* *} \mathrm{R}$ \\
\hline Ratio & MAX & MIN & Mean & SD & ${ }^{*}$ THV & Conf & ${ }^{*}$ THV & Con & ${ }^{*}$ THV & Con & L & H & L & H \\
\hline Peredotit-2 & 0 & 255 & 113.4 & 50.9 & 266.3 & $98 \%$ & 215.3 & $95 \%$ & 164.4 & $92 \%$ & 8 & 3 & 1 & 4 \\
Peredotit-4 & 0 & 255 & 145 & 56.6 & 314.9 & $98 \%$ & 258.2 & $95 \%$ & 201.6 & $92 \%$ & 3 & 5 & 1 & 4 \\
Pyroxenite & 0 & 25 & 116.4 & 57.5 & 289 & $98 \%$ & 231.5 & $95 \%$ & 174 & $92 \%$ & 5 & 4 & 2 & 9 \\
Serpentine & 0 & 255 & 111.7 & 52.6 & 269.6 & $98 \%$ & 216.9 & $95 \%$ & 164.3 & $92 \%$ & 5 & 8 & 6 & 4 \\
Lisweanit & 0 & 255 & 140.3 & 67.3 & 342.1 & $98 \%$ & 274.9 & $95 \%$ & 207.6 & $92 \%$ & 4 & 8 & 7 & 6 \\
\hline
\end{tabular}

${ }^{\star}$ Thershold Value, ${ }^{* *}$ Absorption, ${ }^{* * *}$ Reflection, Conf: Confidence, L: Low, H: High. 


\subsection{Validation}

After identifying stones using FPCS method, determining the images accuracy is absolutely essential because indicates that how well the resulting map corresponds with the ground truth. In this project Davoudzadeh map is used to verify the validation [1]. Sampling is done at the first phase and then we perform validation.

- Sampling: Generally, in this study, random sampling pattern was used. In addition to random mode maintenance, this pattern solves the nonuniform distribution of points [30]. In fact, at first, we identify Statistical Society pixels on the basis of the impact area and spatial resolution. Justice and Townshend in 1981 proposed a useful formula for determining each pixel sample locations area [30] [31]. In Equation (5), $A$ is minimum sample site dimension, $P$ is image pixel dimension and $\mathrm{L}$ refers to estimated locational accuracy in number of pixels which is accurately locate an area on the ground to \pm 0.5 pixel.

$$
A=P(1+2 L)
$$

The amount of $A$ is divided by effect area to determine the population. The maximum number of samples is obtained according to sample size. The Equation (6), Cochran's rule, is one of the most widely used methods for sample size calculation.

Using Cochran formula is the easiest way determining the sample size [32]. The formula elements are as follows: $N$ : Size of population (the population of the city, province, etc), $n$ : Number of samples, $P$ : proportion of the population lacks certain traits (e.g. male population), $t$ or $z$. Percent confidence level of acceptable standard error, d: degree of certainty or potential efficiency, $1-p=q$ proportion of the population lacks certain traits (e.g., women), $p$ and $q$ usually consider as $0.5, Z$ value is usually $1.96, d$ may be 0.01 or 0.05 .

$$
n=\frac{\frac{z^{2} p q}{d^{2}}}{1+\frac{1}{N}\left(\frac{z^{2} p q}{d^{2}}-1\right)}
$$

- Validation: No method is invoked yet its accuracy has been tested. Therefore, accuracy assessment is done to ensure the variety of performed procedures [33]. Validation indicates the extracted maps confidence level and it must be at least $85 \%$ in the images derived from spectral method [34]. Verification means assessing the conformity of images derived from spectral method with ground truth [35] [36]. In this study, we use KAPA and overall accuracy methods.

- Error matrix and Kappa coefficient: Error matrix is an efficient tool for the preparation and presentation of accuracy assessment information. Sometimes, it's called contingency matrix or probability table. Error matrix compares the known relation between reference data (ground truth) and the re- 
levant results of the automated classification [37]. It is a square matrix where the number of rows and columns equal to the number of categories which their classification accuracy was assessed.

$K=($ Observed Agreement $)-($ Expected Agreement $) / 1-$ Expected Agreement (7)

Beside, Kappa coefficient or statistical kappa coefficient is an accuracy evaluation criteria. KAPA index or $K$ is the result of Kapa analysis shown as an index to measure the classification accuracy based on the difference between error matrix accuracy and accuracy changes by sum of rows and columns [38].

In fact, Equation (7) $K$ index indices the disorder between real consistency in reference data and an automated classifier or possible consistency between reference data and random classifier.

When the actual agreement is close to one and expected agreement is close to zero, $K$ value comes to one, so it is the ideal mode [34]. In fact, the Kappa index value is between zero and one, if the amount of kappa is zero indicates a completely random classification and if the amount of kappa is one indicates a quite accurate classification $100 \%$ in accordance with the ground truth [35] [36]. Overall accuracy is the ratio of properly sorted out pixels to total known pixels. Equation (8) indicates the overall accuracy. In this regard $\sum_{i=1}^{N} E_{i i}$ is sum of diagonal elements and $\mathrm{N}$ indices the total pixels or set of elements [38]. In Table 5 the number of points has been sampled using Davoudzadeh geological map based on the Cochran formula and Table 6 shows the validation results.

$$
O A=\frac{\sum_{i=1}^{N} E_{i i}}{N}
$$

\section{Conclusions}

To identify the ophiolitic Mélange, we used the band ratio techniques, composite band, and feature-oriented principal components selection projects. The research results are as follows: the results of the Optimum Index Factor (OIF)

Table 5. The number of sample points.

\begin{tabular}{ccc}
\hline & Area $\left(\mathrm{Km}^{2}\right)$ & ASTER \\
\cline { 3 - 3 } Lithology Unit & 58.5 & ASTER (VNIR + SWIR) \\
\hline Peredotit-2 & 79.15 & 65 \\
Peredotit- 4 & 15 & 13 \\
Listvenite & 48.1 & 42 \\
Pyroxenite & 97.122 & 77 \\
Serpentine & & \\
\hline
\end{tabular}

Table 6. The result of verification.

\begin{tabular}{ccc}
\hline Overall Acc & Kapa & Kapa \% $($ Kapa $\times 100)$ \\
\hline 0.97 & 0.92 & 92 \\
\hline
\end{tabular}


showed the best combination of bands (R: B3, G: B4, B: B8). The maximum number obtained from the OIF for RGB is 0.37210387. The results of Amer band ratio (R: $(\mathrm{B} 2+\mathrm{B} 4) / \mathrm{B} 3$, G: $(\mathrm{B} 5+\mathrm{B} 7) / \mathrm{B} 6, \mathrm{~B}:(\mathrm{B} 7+\mathrm{B} 9) / \mathrm{B} 8)$ are shown as dark pink Chromite, yellow pink Gabbro, orange and pale green Carbonates and dark green vegetation. According to Figure 4, Pyroxenite has absorbed in bond 4 and has reflected with an increasing trend in band 6 and 8. But Serpentine, Peredotit-2, and Peredotit-4 are reflected in band 4 and absorbed in band 8. According to Table 3 and Table 4, the used threshold for detecting Listwanite in PC2 image is calculated with $92 \%$ confidence level, for detecting Peredotit- 2 in PC2 image is calculated with 95\% confidence level, for detecting Pyroxenite in PC1 image is calculated with $95 \%$ confidence level, for detecting Peredotit-4 in PC1 image is calculated with $95 \%$ confidence level and for detecting Serpentine in PC3 image is calculated with $95 \%$ confidence level.

The Justice and the Townshend formulas were used for estimating spatial accuracy based on the sampling pixels (Table 5). The Cochran formula leads to 95\% confidence level for the sampling pixels. The results of Feature Oriented Principal Components Selection (FPCS) are confirmed by Davoudzadeh Geological Map in Figure 1. The Kappa coefficient of 0.92 for the FPCS results is calculated.

\section{References}

[1] Davoudzadeh, M. (1972) Geology and Petrography of the Area North of Nain, Central Iran. Report, Geological Survey of Iran, Tehran, 89 p.

[2] Davoudzadeh, M.M.M. (1972) Geology and Petrography of the Area North of Nain. Central Iran.

[3] Torabi, G. (2012) Central Iran Ophiolites. Iranian Academic Center for Education, Culture and Research, Isfahan (978-600-5051-95-7).

[4] Beiranvand Pour, A.B. and Hashim, M. (2015) Integration of Palsar and Aster Satellite Data for Geological Mapping in Tropics. ISPRS Annals of the Photogrammetry, Remote Sensing and Spatial Information Sciences, 2, 105. https://doi.org/10.5194/isprsannals-II-2-W2-105-2015

[5] Pournamdari, M., Hashim, M. and Pour, A.B. (2014) Application of ASTER and Landsat TM Data for Geological Mapping of Esfandagheh Ophiolite Complex, Southern Iran. Resource Geology, 64, 233-246. https://doi.org/10.1111/rge.12038

[6] Pournamdary, M. and Hashim, M. (2015) The Application of Remote Sensing Techniques for Soghan Ophiolit Study Using ASTER Data.

[7] Tangestani, M.H. and Tayebi, M.H. (2015) Field Work with Satellite Image and Aerial Photographs. Pars Geology Resserch Center (978-600-6058-14-6).

[8] Carranza, E. (2008) Geochemical Anomaly and Mineral Prospectivity Mapping in GIS. Vol. 11, Elsevier.

[9] Abrams, M., Hook, S. and Ramachandran, B. (2002) ASTER User Handbook, Version 2. Jet Propulsion Laboratory, 4800, 135.

[10] Rajendran, S., Al-Khirbash, S., Pracejus, B., Nasir, S., Al-Abri, A.H., Kusky, T.M. and Ghulam, A. (2012) ASTER Detection of Chromite Bearing Mineralized Zones in Semail Ophiolite Massifs of the Northern Oman Mountains: Exploration Strate- 
gy. Ore Geology Reviews, 44, 121-135.

https://doi.org/10.1016/j.oregeorev.2011.09.010

[11] Foudazi, M., Emami, M.H. and Mahabadi, S.A. (2005) Petrography and Mineralogy of Ultamafic Rocks in Nain Ophiolite (Central Iran).

[12] Alai Mahabadi, S.F.M. (2013) Geological Report of the Separu Map (1:25000) Geological Survey and Mineral Explorations Country, 6656 III SW.

[13] Meyer, D., Siemonsma, D., Brooks, B. and Johnson, L. (2015) Advanced Spaceborne Thermal Emission and Reflection Radiometer Level 1 Precision Terrain Corrected Registered At-Sensor Radiance (AST_L1T) Product, Algorithm Theoretical Basis Document (2331-1258).

[14] Green, A.A., Berman, M., Switzer, P. and Craig, M.D. (1988) A Transformation for Ordering Multispectral Data in Terms of Image Quality with Implications for Noise Removal. IEEE Transactions on Geoscience and Remote Sensing, 26, 65-74. https://doi.org/10.1109/36.3001

[15] Amini, J. (2009) Computer Processing of Remote Sensed Image. University of Tehran Press.

[16] Fatemi, S.B. and Rezaei, Y. (2012) Principles of Remote Sensing.

[17] Beauchemln, M. and Fung, K. (2001) On Statistical Band Selection for Image Visualization. Photogrammetric Engineering \& Remote Sensing, 67, 571-574.

[18] Jensen, J.R. (2005) Introductory Digital Image Processing: A Remote Sensing Perspective. Pearson College Division.

[19] Vincent, R.K. (1997) Fundamentals of Geological and Environmental Remote Sensing. Vol. 366, Prentice Hall, Upper Saddle River.

[20] Tangestani, M.H. (2009) Fundamentals of Geological and Environmental Remote Sensing. IUP.

[21] Amer, R., Kusky, T. and Ghulam, A. (2010) Lithological Mapping in the Central Eastern Desert of Egypt using ASTER Data. Journal of African Earth Sciences, 56, 75-82.

[22] Elsaid, M., Aboelkhair, H., Dardier, A., Hermas, E. and Minoru, U. (2014) Processing of Multispectral ASTER Data for Mapping Alteration Minerals Zones: As an Aid for Uranium Exploration in Elmissikat-Eleridiya Granites, Central Eastern Desert, Egypt. The Open Geology Journal, 8, 69-83. https://doi.org/10.2174/1874262901408010069

[23] Baldridge, A., Hook, S., Grove, C. and Rivera, G. (2009) The ASTER Spectral Library Version 2.0. Remote Sensing of Environment, 113, 711-715.

[24] Rajendran, S., Nasir, S., Kusky, T.M., Ghulam, A., Gabr, S. and El-Ghali, M.A. (2013) Detection of Hydrothermal Mineralized Zones Associated with Listwaenites in Central Oman using ASTER Data. Ore Geology reviews, 53, 470-488.

[25] Jolliffe, I. (2002) Principal Component Analysis. Wiley Online Library.

[26] Crosta, A. and Moore, J. (1990) Enhancement of Landsat Thematic Mapper Imagery for Residual Soil Mapping in SW Minas Gerais State, Brazil-A Prospecting Case History in Greenstone Belt Terrain. The Thematic Conference on Remote Sensing for Exploration Geology: Methods, Integration, Solutions, Calgary.

[27] Honarmand, M. and Ranjbar, H. (2005) Application of Different Image Processing Techniques on Etm+ Images for Exploration of Porphyry and Vein Type Copper Mineralizations in Kuh-e-mamzar and Kuh-e-panj Areas, Kerman Province. Geosciences Scientific Quarterly Journal. 
[28] Crosta, A., De Souza Filho, C., Azevedo, F. and Brodie, C. (2003) Targeting Key Alteration Minerals in Epithermal Deposits in Patagonia, Argentina, using ASTER Imagery and Principal Component Analysis. International Journal of Remote Sensing, 24, 4233-4240. https://doi.org/10.1080/0143116031000152291

[29] Sharghi, N.A., Aslani, S. and Bahroudi, A. (2011) Identification of Hydrothermal Alteration Zones using Aster Data in the Tarom Area, Zanjan.

[30] McCoy, R.M. (2005) Field Methods in Remote Sensing. Guilford Press.

[31] Townshend, J. and Justice, C. (1981) Information Extraction from Remotely Sensed Data. A User View. Remote Sensing, 2, 313-329. https://doi.org/10.1080/01431168108948367

[32] Cochran, W.G. (2007) Sampling Techniques. John Wiley \& Sons, Hoboken.

[33] Alavi panah, S.K. (2010) Application of Remote Sensing in the Earth Science (Soil). University of Tehran.

[34] Rasouli, A. (2009) Principles and Applied Remote Sensing Satellite Image Processing. Presses Universitaires de Tabriz.

[35] Lefsky, M.A. and Cohen, W.B. (2003) Selection of Remotely Sensed Data Remote Sensing of Forest Environments. Springer, Berlin, 13-46. https://doi.org/10.1007/978-1-4615-0306-4_2

[36] Smits, P., Dellepiane, S. and Schowengerdt, R. (1999) Quality Assessment of Image Classification Algorithms for Land-Cover Mapping: A Review and a Proposal for a Cost-Based Approach. International Journal of Remote Sensing, 20, 1461-1486. https://doi.org/10.1080/014311699212560

[37] Lillesand, T., Kiefer, R. and Chipman, J. (2000) Remote Sensing and Image Analysis. John Wiley and Sons, New York.

[38] Yoyusefi, S., Tazeh, M., Mirzaee, S., Moradi, H. and Tavangar, S. (2014) Comparison of Different Classification Algorithms in Satellite Imagery to Produce Land Use Maps (Case Study: Noor City).

Submit or recommend next manuscript to SCIRP and we will provide best service for you:

Accepting pre-submission inquiries through Email, Facebook, LinkedIn, Twitter, etc. A wide selection of journals (inclusive of 9 subjects, more than 200 journals)

Providing 24-hour high-quality service

User-friendly online submission system

Fair and swift peer-review system

Efficient typesetting and proofreading procedure

Display of the result of downloads and visits, as well as the number of cited articles

Maximum dissemination of your research work

Submit your manuscript at: http://papersubmission.scirp.org/

Or contact ojg@scirp.org 